\title{
In memory of Marco Leonardi
}

\author{
Mario Muto $^{1}$ - Alberto Beltramello ${ }^{2}$
}

Published online: 8 June 2017

(C) Springer-Verlag Berlin Heidelberg 2017

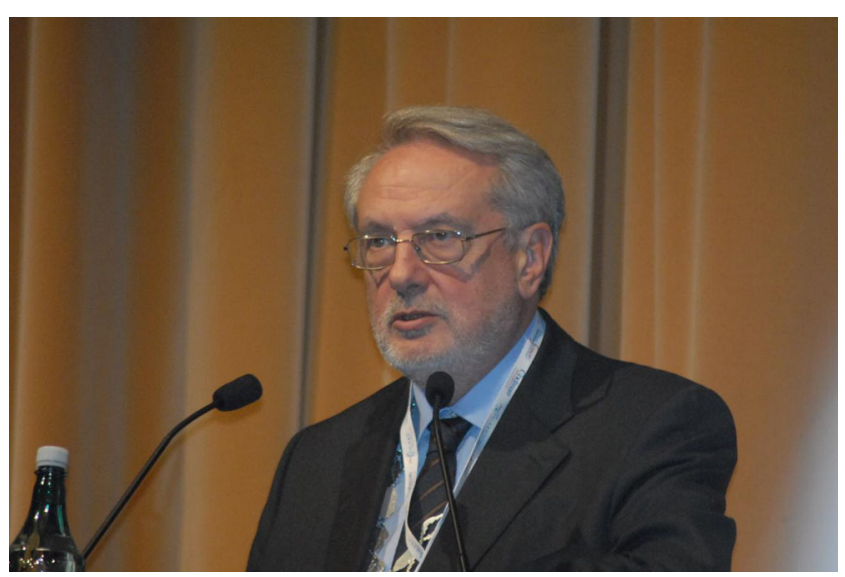

Marco Leonardi was born in Rome in 1944. He got the degree in Medicine and Surgery in 1967 and 2 years later, he became a specialist in radiology in Padua. He was also a short-term fellow of Giovanni Ruggiero, one of the founders of European Neuroradiology, but he left soon his master to be nominated Chief of Neuroradiology in Udine where he stayed 13 years before moving to the University of Milan where he became a full professor of neuroradiology.

Finally, he moved back to his Bologna in 1996 at Bellaria Hospital. He retired only 2 years ago. He has been an innovator,

\section{Mario Muto}

mutomar2@gmail.com

1 Diagnostic and Interventional Neuroradiology, Cardarelli Hospital, Naples, Italy

2 Scientific Consultant in Neuroradiology, Sacro Cuore Hospital, Negrar, Italy pioneer, and curious scientist able to understand in which direction the medical world was going. His department has been one of the first filmless in Europe such as one of the first center to have 3T MR and Biplane DSA.

Marco loved to teach and to transmit his enthusiasm and his experience to young fellows.

He was the founder and Editor of two international journals such as The Neuroradiology Journal and Interventional Neuroradiology.

$\mathrm{He}$ has been elected President of AINR twice (Associazione Italiana di Neuroradiologia) and Secretary General and President of ESNR (European Society of Neuroradiology), and he was an active member of WFITN (World Federation of Interventional Neuroradiology). He has been also the President of the Italian and ESNR Annual Meeting of Neuroradiology, President of WFITN Meeting, and President of Symposium Neuroradiologicum.

He was a fully dedicated doctor and a master, with human capacity and a strong didactic attitude featured by actions and not only by theory. His practical sense in daily life brought him to solve problems in a very rational, simple, and effective way.

We lose a colleague and a master; we lose a scientist, but we lose especially a best friend you can imagine to have, ready to listen to you in case of need, discrete and reserved in his suggestions, and a real guide.

We want to share to all in the neuroradiological world this sense of gratitude and affection to him and also to his wife, Adriana, and his son, Nicola.

Thanks Marco, we miss you, and we will keep in our daily works your teaching message!

Mario Muto, Alberto Beltramello 